REGARDS

SUR L'ECONOMIE ALLEMANDE

BULLETIN ECONOMIQUE DU CIRAC
Regards sur l'économie allemande

Bulletin économique du CIRAC

116-117| 2015

Varia

\title{
Transition énergétique
}

CHRISTEN Guillaume, HAMMAN Philippe, JEHLING Mathias, WINTZ Maurice (dir.), Systèmes énergétiques renouvelables en France et en Allemagne - Synergies et divergences

\section{(2) OpenEdition}

Édition électronique

URL : http://journals.openedition.org/rea/4866

DOI : $10.4000 /$ rea. 4866

ISSN : 1965-0787

Éditeur

CIRAC

\section{Édition imprimée}

Date de publication : 1 juillet 2015

Pagination : 76

ISSN : 1156-8992

\section{Référence électronique}

"Transition énergétique », Regards sur l'économie allemande [En ligne], 116-117 | juillet 2015, mis en ligne le 01 juillet 2015, consulté le 22 septembre 2020. URL : http://journals.openedition.org/rea/4866 ; DOI : https://doi.org/10.4000/rea.4866

Ce document a été généré automatiquement le 22 septembre 2020.

(c) CIRAC 


\section{Transition énergétique}

CHRISTEN Guillaume, HAMMAN Philippe, JEHLING Mathias, WINTZ Maurice (dir.), Systèmes énergétiques renouvelables en France et en Allemagne - Synergies et divergences

\section{RÉFÉRENCE}

CHRISTEN Guillaume, HAMMAN Philippe, JEHLING Mathias, WINTZ Maurice (dir.), Systèmes énergétiques renouvelables en France et en Allemagne - Synergies et divergences, Coll. Universités, Orizons, Paris, 2014, 330 p.

1 Cet ouvrage collectif dépasse parfois le cadre des énergies renouvelables pour se pencher sur la sobriété énergétique, ou encore l'enjeu du captage, du transport et du stockage du $\mathrm{CO}_{2}$. Une large part de l'analyse est consacrée à l'acceptation de la transition énergétique par les citoyens et à leur participation à ce processus qui revêt, outre une dimension technique, des aspects à la fois politiques, sociaux et territoriaux. (Solène Hazouard) 